\title{
Época de desfolha e sua influência no desempenho vitícola da uva 'Sauvignon Blanc' em região de elevada altitude
}

\author{
Leaf removal timing and its influence on wine grape performance 'Sauvignon Blanc' in high altitude \\ region
}

\author{
Douglas André Würz ${ }^{1 *}$, Ricardo Allebrandt', José Luiz Marcon Filho ${ }^{2}$, Betina Pereira de Bem ${ }^{1}$, Alberto \\ Fontanella Brighenti ${ }^{3}$, Leo Rufato ${ }^{1}$ \& Aike Anneliese Kretzschmar ${ }^{1}$ \\ ${ }^{1}$ Universidade do Estado de Santa Catarina, Lages, SC, Brasil. *Autor para correspondência: douglaswurz@hotmail.com. \\ 2 Vinícola Legado, Campo Largo, PR, Brasil. \\ ${ }^{3}$ Empresa de Pesquisa Agropecuária e Extensão Rural de Santa Catarina, São Joaquim, SC, Brasil.
}

Submissão: 03/05/2017 | Aceite: 08/02/2018

\begin{abstract}
RESUMO
A videira caracteriza-se como uma espécie exigente em tratos culturais, e para se alcançarem condições ótimas no momento da colheita, é fundamental que as técnicas de manejo sejam adequadas às características de cada região. A desfolha, nesse sentido, tem sido uma importante ferramenta de manejo do dossel vegetativo, podendo melhorar a composição química dos cachos e aumentar a eficiência produtiva da videira. O objetivo deste trabalho foi avaliar o manejo da desfolha em diferentes estádios fenológicos, sobre a eficiência produtiva e na composição química dos cachos da variedade Sauvignon Blanc cultivada em regiões de altitude. O experimento foi conduzido nas safras 2015 e 2016 , em um vinhedo localizado no município de São Joaquim, SC (28`17'39"S e 4955'56”W, 1230m). Os tratamentos consistiram em diferentes épocas de desfolhas, realizadas na região dos cachos nos estádios fenológicos: plena florada, grão chumbinho, grão ervilha, virada de cor das bagas, 15 dias após a virada de cor e sem desfolha (testemunha). Os dados foram submetidos à análise de variância (ANOVA) e comparados pelo Teste Scott-Knott a $5 \%$ de probabilidade de erro. Observou-se que a desfolha realizada até o estádio fenológico virada de cor propicia incremento no índice de fertilidade. O manejo da desfolha realizado nos estádios fenológicos grão ervilha e virada de cor apresentaram as maiores produtividades em relação aos demais estádios fenológicos e plantas não submetidas ao manejo da desfolha. Além disso, o manejo da desfolha melhorou a maturação tecnológica e fenólica da uva Sauvignon Blanc quando realizada nos estádios fenológicos grão chumbinho e grão ervilha, nas duas safras avaliadas. Os resultados deste trabalho evidenciam a importância no manejo da desfolha para obtenção de um mosto com potencial para elaboração de vinhos finos de qualidade, principalmente quando realizados entre os estádios fenológicos de grão chumbinho e grão ervilha. Portanto, a desfolha da videira Sauvignon Blanc em regiões de altitude deve ser considerada uma prática de manejo indispensável ao vitivinicultor.
\end{abstract}

PALAVRAS-CHAVE: Vitis vinifera L., manejo do dossel, desfolha precoce, vinhos de altitude.

\section{ABSTRACT}

The winegrape is characterized as a demanding species in cultural dealings and in order to reach optimal conditions at the time of harvest it is fundamental that the management techniques are adequate the characteristics of each region, being the leaf removal has been an important management of the vegetative canopy, which can improve the chemical composition of the bunches and increase the productive efficiency of the vine. The objective of this study was to evaluate the leaf removal effect on the agronomic performance and maturation ad the productive efficiency of the Sauvignon Blanc grape in high altitude regions of Santa Catarina. The experiment was conducted in 2015 and 2016 vintages, in a commercial vineyard, located in São Joaquim, Santa Catarina State (28¹7'39"S; 4955'56"W, altitude $1,230 \mathrm{~m}$ a.s.I.). The leaf removal was carried out in cluster zone in the following phenological stages: full bloom, buckshot berries, pea-sized berries, veraison, 15 days after veraison and control without leaf removal. The results were submitted to analysis of variance and Scott-Knott test ( $5 \%$ probability). It was observed that the leaf removal carried before veraison increase the fertility index. The leaf removal carried out in the phenological pea-sized berries and veraison presented the highest yields in relation to the other phenological stages and plants not submitted to the management of leaf removal. In addition, the leaf removal improved the technological and phenolic maturation of the Sauvignon Blanc grape when it was 
carried out in the phenological stages buckshot berries and pea-sized berries in the two harvests evaluated. The results of this study evidenced the importance the leaf removal to obtain a must with potential for the elaboration of quality fine wines, especially when carried out between the phenological stages of buckshot berries and pea-sized berries. Therefore, the leaf removal of the Sauvignon Blanc grapevine in high altitude regions should be considered an indispensable management practice for the vitivinicultor.

KEYWORDS: Vitis vinifera L., canopy management, early leaf removal, wines of altitude.

\section{INTRODUÇÃO}

A vitivinicultura nas regiões de altitude do estado Santa Catarina, embora recente, apresenta grande importância econômica, sendo esse estado o segundo maior produtor de uvas destinadas à elaboração de vinhos finos no Brasil. Observam-se nessas regiões ciclos fenológicos mais prolongados em comparação a outras regiões vitivinícolas brasileiras, isso ocorre pelas menores temperaturas noturnas e maior amplitude térmica, produzindo assim uvas com elevada qualidade enológica (MALINOVSKI et al. 2016).

A uva 'Cabernet Sauvignon' é a variedade com a maior área de produção nas regiões de elevadas altitudes de Santa Catarina, correspondendo a 37\% da área plantada (VIANNA et al. 2016). No entanto, é uma variedade de ciclo longo, que necessita maior soma térmica (1.200 graus dias) para completar suas fases fenológicas, sendo sua colheita realizada a partir da segunda quinzena de abril, época em que são registradas quedas consideráveis de temperatura na região (BRIGHENTI et al. 2013). Por consequência, em anos frios e chuvosos, corre-se o risco de se colher uvas 'Cabernet Sauvignon' com parâmetros inadequados de maturação, como elevado teor de acidez e excesso de aromas herbáceos.

Nesse contexto, a variedade Sauvignon Blanc vem surgindo como alternativa de substituição da Cabernet Sauvignon nos últimos anos para produção de vinhos finos nas regiões de altitude de Santa Catarina, com aumento de $68,9 \%$ na área de vinhedos (VIANNA et al. 2016). Os vinhos de 'Sauvignon Blanc' elaborados no terroir em questão apresentam características específicas: alta complexidade, qualidade aromática e tipicidade, o que os diferencia de vinhos de 'Sauvignon Blanc' elaborados em outras regiões vitícolas, devido à adaptação desta variedade às condições edafoclimáticas da região de altitude catarinense (BRIGHENTI et al. 2013, MARCON FILHO 2016). No entanto, a maioria das técnicas de manejo empregadas nos vinhedos, entre elas a desfolha, foram baseadas nas experiências de produtores e técnicos, bem como resultados de pesquisas oriundas de outras regiões vitivinícolas já consolidadas no setor. Entretanto, a aplicação dessas técnicas nem sempre corresponde com as situações encontradas nas regiões de altitude.

A videira caracteriza-se como uma espécie exigente em tratos culturais, e para alcançar condições ótimas no momento da colheita é fundamental que as técnicas de manejo sejam adequadas às características de cada região (MARCON FILHO et al. 2015). Entre as diversas técnicas de manejo, que têm sido desenvolvidas com o objetivo de otimizar a interceptação da luz solar, a capacidade fotossintética da planta, e o microclima dos cachos para melhorar a produção e a qualidade dos vinhos, especialmente em variedades que apresentam excesso de vigor (JOGAIAH et al. 2013), o manejo da desfolha apresenta grande importância.

Diversos trabalhos científicos confirmam que a desfolha tem sido uma importante ferramenta de manejo do dossel vegetativo, podendo reduzir a compactação do cacho, reduzir a ocorrência de podridões de cachos, além de melhorar a composição química dos cachos (PONI et al. 2008, LOHITNAVY et al. 2010, TARDAGUILA et al. 2012). Apesar de ser um manejo comum da videira (LEÃO et al. 2016), o estádio fenológico mais apropriado para sua realização ainda gera dúvidas.

Tradicionalmente, a realização do manejo da desfolha ocorre no momento da virada de cor ou "veráison", no entanto, a desfolha precoce pode ser considerada um manejo inovador da videira (DIAGO et al. 2010). Se realizada próximo ao estádio fenológico da florada, pode ocasionar redução da produção e incremento dos níveis de sólidos solúveis e concentrações de antocianinas (INTRIERI et al. 2008, PONI et al. 2009). Além desses efeitos, a desfolha precoce, realizada anteriormente ao estádio fenológico virada de cor, melhora a exposição solar e a circulação de ar (BLEDSOE et al. 1988, TARDAGUILA et al. 2010). Estudo realizado sobre o efeito da exposição solar sobre características sensoriais do vinho mostrou que 0 sombreamento dos cachos pode alterar compostos que influenciam as qualidades organolépticas do vinho (RISTIC et al. 2007).

O presente trabalho teve como objetivo avaliar o manejo da desfolha em diferentes estádios fenológicas, sobre a eficiência produtiva e na composição química dos cachos da variedade Sauvignon 
Blanc cultivada em regiões de altitude. Tendo em vista o aumento do plantio da variedade Sauvignon Blanc nas regiões de altitude, a sua adaptação e qualidade da uva e do vinho nas regiões de elevada altitude (BORGHEZAN et al. 2014), e a carência de informações científicas referentes ao manejo da desfolha desta variedade.

\section{MATERIAL E MÉTODOS}

O presente estudo foi realizado nas safras 2015 e 2016, em um vinhedo comercial (coordenadas 28우 17' 39" S e 495 5' 56" O, a 1.230m de altitude), situado no município de São Joaquim, Santa Catarina. O clima da região é classificado como 'Frio, Noites Frias e Úmido', Índice Heliotérmico de 1.714, precipitação pluvial média anual de $1.621 \mathrm{~mm}$ e a umidade relativa do ar média anual de 80\% (TONIETTO \& CARBONNEAU 2004).

Foi utilizada do vinhedo a variedade Sauvignon Blanc, enxertada sobre "Paulsen 1103", implantado em 2004. O vinhedo caracteriza-se por apresentar espaçamento $3,0 \times 1,5$, em filas dispostas no sentido Norte-Sul, conduzidas em espaldeira em cordão esporonado a 1,2 $\mathrm{m}$ de altura do solo e cobertas com tela branca de proteção anti-granizo.

O delineamento experimental utilizado foi o de blocos ao acaso, com quatro blocos e cinco plantas por parcela. Os tratamentos consistiram na realização da desfolha, expondo a região dos cachos em cinco diferentes estágios fenológicos, utilizando a escala descrita por BAILLOD \& BAGGIOLINI (1993): plena florada, grão chumbinho, grão ervilha, virada de cor, 15 dias após a virada de cor e plantas sem desfolha (testemunha). A desfolha foi realizada manualmente, retirando-se três folhas basais, inclusive a folha oposta ao cacho, expondo completamente os cachos da videira. Os demais tratos culturais (poda, desbrota, desponte e tratamentos fitossanitários) foram realizados pela empresa de acordo com as recomendações dos responsáveis técnicos, em todos os tratamentos.

A data da colheita foi determinada seguindo os padrões da vinícola, 24 de fevereiro de 2015 e 18 de fevereiro de 2016. No momento da colheita, quantificou-se o número de ramos por planta de cada parcela. Para cálculo da produtividade foram selecionadas duas plantas por parcela para obtenção das variáveis números de cachos e produção $(\mathrm{kg})$. A produtividade estimada $\left(\mathrm{t} \mathrm{ha}^{-1}\right)$ foi obtida através da multiplicação da produção por planta pela densidade de plantio (2222 plantas ha-1). O índice de fertilidade foi obtido pela relação entre o número de cachos por planta e número de ramos por plantas, determinados no momento da colheita.

A estimativa da área foliar foi realizada durante a colheita das uvas. Foram selecionados 10 sarmentos por tratamento, localizados no terço médio do cordão esporonado. Mediu-se o comprimento da nervura central de todas as folhas do sarmento utilizando uma régua graduada $\mathrm{em} \mathrm{cm}$. A área foliar total por ramo foi obtida segundo os modelos matemáticos propostos por BORGHEZAN et al. (2010). Para a variedade 'Sauvignon Blanc' foi utilizada a seguinte equação: $y=1,0968 x^{2,1628}$. Onde, " $y$ " corresponde à área foliar a ser estimada em $\mathrm{cm}^{2} \mathrm{e}$ " $x$ " corresponde ao comprimento da nervura central da folha em $\mathrm{cm}$.

No momento das colheitas, foram coletadas 150 bagas por parcela para análise da maturação tecnológica e fenólica. As bagas foram esmagadas para separação do mosto e das cascas. A partir do mosto, foram determinados o teor de sólidos solúveis (SS), acidez titulável (AT) e pH, através de metodologias oficiais da Organização Internacional da Vinha e do Vinho (OIV 2009). O teor de SS foi mensurado em refratômetro digital modelo ITREFD-45, sendo os resultados expressos em ${ }^{\circ}$ Brix. A AT foi obtida através da titulação do mosto com solução alcalina padronizada de hidróxido de sódio $0,1 \mathrm{~N}$, utilizando como indicador o azul de bromotimol, sendo os resultados expressos em meq L-1. O potencial hidrogeniônico $(\mathrm{pH})$ foi registrado por meio de um potenciômetro de bancada marca lon, modelo Phb500, após calibração em soluções tampões conhecidas de pH 4,0 e 7,0.

O índice de polifenóis totais (IPT) nas cascas foi determinado de acordo com metodologia proposta por GLORIES (1998) e RIBÉREAU-GAYON et al. (1998). A coloração (Abs $420 \mathrm{~nm}$ ) foi analisada em espectrofotômetro UV-VIS (Biospectro - Modelo SP220). Todas as análises foram realizadas em duplicata.

Para a obtenção das soluções-extrato, foi utilizada a metodologia descrita por MARCON FILHO et al. (2015), por meio da qual foram separadas manualmente $100 \mathrm{~g}$ de cascas a partir das amostras de bagas, às quais foram adicionados $40 \mathrm{~mL}$ de solução hidroalcóolica de metanol $50 \% \mathrm{v} \mathrm{v}^{-1}$, e mantidas a $30{ }^{\circ} \mathrm{C}$ $\left(+0,5^{\circ} \mathrm{C}\right)$ por 24 horas. Após este período, o extrato obtido foi reservado e adicionou-se novamente $40 \mathrm{~mL}$ da solução extratora de metanol às cascas, que, em seguida, foram colocadas em BOD, para a extração a $0{ }^{\circ} \mathrm{C}\left(+0,5{ }^{\circ} \mathrm{C}\right)$ por mais 24 horas. As soluções da primeira e segunda extração foram homogeneizadas e filtradas ao final do processo. 
Os dados meteorológicos foram obtidos a partir de Estação Meteorológica Automática Telemétrica do Centro de Informações de Recursos Ambientais e de Hidrometeorologia de Santa Catarina (EPAGRI/CIRAM), localizada na Estação Experimental da EPAGRI em São Joaquim. Os parâmetros meteorológicos foram: temperatura média do ar $\left({ }^{\circ} \mathrm{C}\right)$ e precipitação pluviométrica $(\mathrm{mm})$ diária durante os meses de novembro a abril das safras 2014/2015 e 2015/2016, que coincidem com o intervalo de estádios fenológicos plena florada e colheita (Figura 1).

Os dados foram submetidos à análise de variância (ANOVA) e as médias comparadas pelo teste Scott-Knott a 5\% de probabilidade de erro.
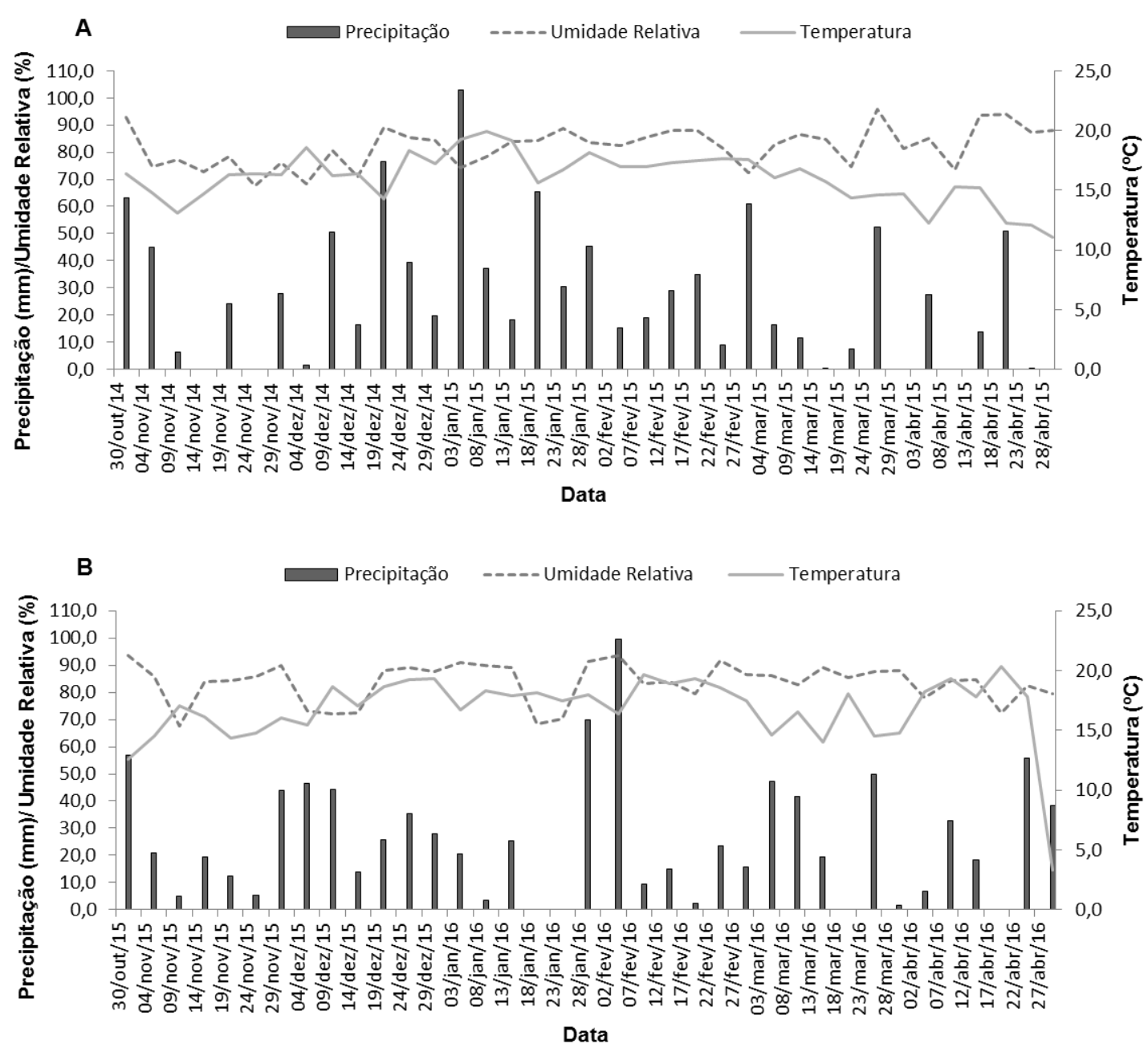

Figura 1. Precipitação pluviométrica acumulada $(\mathrm{mm})$, umidade relativa do ar (\%) e temperatura média do ar $\left({ }^{\circ} \mathrm{C}\right)$ para São Joaquim, SC de outubro de 2014 a abril de 2015 (A) e de outubro de 2015 à abril de 2016 (B).

Figure 1. Cumulative rainfall $(\mathrm{mm})$, relative air humidity $(\%)$ and mean air temperature $\left({ }^{\circ} \mathrm{C}\right)$ in São Joaquim, Santa Catarina State, Brazil, from October 2014 to April 2015 (A) and from October 2015 to April 2016.

\section{RESULTADOS E DISCUSSÃO}

A temperatura média, umidade relativa do ar e o volume de chuvas acumuladas durante o ciclo vegetativo da videira (Novembro a Abril) foram similares nas duas safras avaliadas, apresentando no ciclo 2014/2015 médias de $16 \stackrel{\circ}{\circ}$, 82,1\% e $1019 \mathrm{~mm}$ e no ciclo 2015/2016 de 16,8 $\stackrel{\circ}{ } \mathrm{C}, 83,6 \%$ e 953,4 mm (Figura 1), no entanto, verificou-se na safra 2015/2016 um período de elevados volumes de chuvas durante a maturação da videira Sauvignon Blanc (início do mês de fevereiro), resultando na colheita precoce dessas uvas, a fim de evitar perdas por podridões de cachos.

Em relação ao número de cachos por planta, não foram observadas diferenças estatisticamente significativas na safra 2015. No entanto, na safra 2016, as desfolhas realizadas nos estádios fenológicos 
plena florada, grão chumbinho, grão ervilha e virada de cor apresentaram maior número de cachos em comparação com as plantas desfolhadas 15 dias após a virada de cor e plantas não submetidas ao manejo da desfolha. Esse aumento no número de cachos por planta está relacionado com o incremento do índice de fertilidade (número de cachos por planta) nos estádios fenológicos plena florada, grão chumbinho, grão ervilha e virada de cor, em função da desfolha (Tabela 1). Verificou-se que a desfolha realizada no estádio fenológico 15 dias após a virada de cor e as plantas não submetidas ao manejo da desfolha resultou em uma redução do índice de fertilidade da safra 2015 para a safra 2016, ocasionado pelo sombreamento das gemas pela não realização do manejo da desfolha. A formação da gema fértil é a consequência da diferenciação do primórdio indiferenciado em primórdio reprodutivo (BOTELHO et al. 2006), sendo a intensidade luminosa o fator climático mais limitante para a formação de gemas férteis. Condições insatisfatórias de luz durante a iniciação da inflorescência reduzem severamente a fertilidade de gemas e ramos mais expostos à luz, normalmente são mais férteis (BOWEN \& KLIEWER 1990, KELLER \& KOBLET 1995), sendo assim a retirada das folhas nas regiões dos cachos expõe as gemas à exposição solar (TARDAGUILA et al. 2010), afetando assim a fertilidade das gemas, e consequentemente aumentando o número de cachos por ramo.

Tabela 1. Efeito das épocas de desfolha no número de cachos, número de ramos e índice de fertilidade da videira Vitis vinifera L. var. Sauvignon Blanc em região de altitude elevada de Santa Catarina. Safra 2015 e 2016.

Table 1. Effect of leaf removal timing on number of cluster, numers of shoots en fertility index of Sauvignon Blanc (Vitis vinifera L.) in high altitude regions of Santa Catarina State, Brazil. Vintage 2015 and 2016.

\begin{tabular}{|c|c|c|c|c|c|c|}
\hline \multirow[t]{2}{*}{ Época de Desfolha } & \multicolumn{2}{|c|}{$\begin{array}{l}\text { Número de Cachos } \\
\left(\text { cachos planta-1 }^{-1}\right)\end{array}$} & \multicolumn{2}{|c|}{$\begin{array}{l}\text { Número de Ramos } \\
\text { (ramos planta-1) }\end{array}$} & \multicolumn{2}{|c|}{$\begin{array}{l}\text { Índice de Fertilidade } \\
\text { (número cachos ramo }{ }^{-1} \text { ) }\end{array}$} \\
\hline & 2015 & 2016 & 2015 & 2016 & 2015 & 2016 \\
\hline Plena Florada & $45 \mathrm{~ns}$ & $40 \mathrm{~b}$ & $41 \mathrm{~ns}$ & $35 \mathrm{~ns}$ & $1,10 \mathrm{~ns}$ & $1,16 \mathrm{~b}$ \\
\hline Grão Chumbinho & 49 & $40 \mathrm{~b}$ & 45 & 36 & 1,12 & $1,11 \mathrm{~b}$ \\
\hline Grão Ervilha & 50 & $40 \mathrm{~b}$ & 44 & 34 & 1,12 & $1,17 b$ \\
\hline Virada de Cor & 54 & $43 \mathrm{~b}$ & 46 & 36 & 1,12 & $1,20 b$ \\
\hline 15 dias após Virada de Cor & 57 & $34 \mathrm{a}$ & 44 & 36 & 1,15 & $0,92 \mathrm{a}$ \\
\hline Sem Desfolha & 51 & $37 \mathrm{a}$ & 45 & 38 & 1,15 & $0,90 \mathrm{a}$ \\
\hline CV (\%) & 10,2 & 7,6 & 9,9 & 8,6 & 8,0 & 12,7 \\
\hline
\end{tabular}

${ }^{*}$ Médias seguidas da mesma letra, na coluna, não diferem entre si pelo teste Scott-Knott a 5\% de probabilidade de erro. $\mathrm{ns}=$ não significativo.

Para as variáveis produção e produtividade, observou-se comportamento similar nas duas safras avaliadas (Tabela 2). As desfolhas realizadas nos estádios fenológicos grão ervilha e virada de cor resultaram em maior produção por planta e produtividade nas duas safras avaliadas. $O$ mecanismo fisiológico subjacente à remoção precoce das folhas baseia-se no fato de que as folhas basais são a principal fonte de assimilados na floração e logo após a floração e, portanto, são fatores determinates no rendimento (CASPARI \& LANG 1996, PONI et al. 2006). Assim, espera-se uma redução do rendimento da videira quando a desfolha é realizada precocemente (DIAGO et al. 2010). Quando realizada no estádio fenológico plena florada, é comum verificar-se redução da produtividade (PONI et al. 2006), no entanto, não se verificou tal comportamento nesse trabalho, o que pode ser explicado pelo incremento do índice de fertilidade ocasionada pela desfolha realizada no estádio fenológico plena florada.

Um dos benefícios da desfolha é a redução do índice de área foliar, controlando o excesso de crescimento vegetativo, como consequência do aumento da densidade do dossel vegetativo e da melhor exposição dos cachos de uva ao sol (TARDAGUILA et al. 2010). Durante a safra 2015, verificou-se redução da área foliar total das plantas submetidas ao manejo da desfolha, sendo que a desfolha realizada no estádio fenológico grão ervilha propiciou maior redução da área foliar. Estudo realizado por CHORTI et al. (2010) verificou redução da área ocasionada pela remoção das folhas basais, proporcionando redução da disponibilidade de carboidratos para a planta.

No entanto, na safra 2016, verificou-se redução da área foliar apenas quando a desfolha foi realizada no estádio fenológico plena florada, já nas demais épocas de desfolha não se observaram diferenças 
estatisticamente significativas em relação às plantas não submetidas ao manejo da desfolha. Esse comportamento pode ser explicado pelo menor número de ramos e menor número de cachos na safra 2016, que propiciou maior crescimento vegetativo, visto que quando há excesso de vigor, as videiras não param de crescer (BORGHEZAN et al. 2014). Estudo realizado por DIAGO et al. (2012) verificou redução da área foliar no momento da realização da desfolha, no entanto, as videiras recuperaram sua área foliar e obtiveram no momento da colheita valores semelhantes as plantas não submetidas ao manejo de desfolha.

Tabela 2. Efeito das épocas de desfolha na produção, produtividade e área foliar da videira Vitis vinifera $\mathrm{L}$. var. Sauvignon Blanc em região de altitude elevada de Santa Catarina. Safra 2015 e 2016.

Table 2. Effect of leaf removal timing on productive variables and leaf area of Sauvignon Blanc (Vitis vinifera L.) in high altitude regions of Santa Catarina State, Brazil. Vintage 2015 and 2016.

\begin{tabular}{ccccccc}
\hline \multirow{2}{*}{ Época de Desfolha } & \multicolumn{2}{c}{$\begin{array}{c}\text { Produção } \\
\left(\mathrm{kg} \mathrm{planta}^{-1}\right)\end{array}$} & $\begin{array}{c}\text { Produtividade } \\
\left(\mathrm{t} \mathrm{ha}^{-1}\right)\end{array}$ & \multicolumn{2}{c}{$\begin{array}{c}\text { Área Foliar } \\
\left(\mathrm{cm}^{2}\right)\end{array}$} \\
\cline { 2 - 7 } & 2015 & 2016 & 2015 & 2016 & 2015 & 2016 \\
\hline Plena Florada & $3,9 \mathrm{a}$ & $2,6 \mathrm{a}$ & $8,7 \mathrm{a}$ & $5,9 \mathrm{a}$ & $13,0 \mathrm{~d}$ & $14,6 \mathrm{a}$ \\
Grão Chumbinho & $4,2 \mathrm{a}$ & $2,8 \mathrm{a}$ & $9,4 \mathrm{a}$ & $6,3 \mathrm{a}$ & $12,2 \mathrm{c}$ & $16,5 \mathrm{~b}$ \\
Grão Ervilha & $6,0 \mathrm{~b}$ & $3,3 \mathrm{~b}$ & $13,4 \mathrm{~b}$ & $7,4 \mathrm{~b}$ & $10,4 \mathrm{a}$ & $17,0 \mathrm{~b}$ \\
Virada de Cor & $6,4 \mathrm{~b}$ & $3,4 \mathrm{~b}$ & $14,3 \mathrm{~b}$ & $7,7 \mathrm{~b}$ & $11,5 \mathrm{~b}$ & $18,6 \mathrm{~b}$ \\
15 dias após Virada de Cor & $4,7 \mathrm{a}$ & $2,6 \mathrm{a}$ & $10,4 \mathrm{a}$ & $5,8 \mathrm{a}$ & $13,9 \mathrm{e}$ & $17,2 \mathrm{~b}$ \\
Sem Desfolha & $4,3 \mathrm{a}$ & $2,9 \mathrm{a}$ & $9,5 \mathrm{a}$ & $6,5 \mathrm{a}$ & $16,4 \mathrm{f}$ & $17,4 \mathrm{~b}$ \\
\hline CV (\%) & 12,5 & 12,6 & 13,4 & 12,5 & 8,6 & 5,6 \\
\hline
\end{tabular}

*Médias seguidas da mesma letra, na coluna, não diferem entre si pelo teste Scott-Knott a 5\% de probabilidade de erro. ns = não significativo.

Para as avaliações de maturação tecnológica, verificou-se influência das diferentes épocas de desfolha da videira Sauvignon Blanc (Tabela 3). Na safra 2015, observou-se incremento do conteúdo de sólidos solúveis nas plantas desfolhas nos estádios fenológicos grão chumbinho e grão ervilha, e os demais estádios fenológicos não diferiram estatisticamente das plantas não submetidas ao manejo da desfolha. Já na safra 2016, verificou-se incremento do conteúdo de sólidos solúveis nas plantas submetidas à desfolha nos estádios fenológicos plena florada, grão chumbinho e grão ervilha.

Tabela 3. Efeito das épocas de desfolha na maturação tecnológica dos cachos da videira Vitis vinifera L. var. Sauvignon Blanc em região de altitude elevada de Santa Catarina. Safra 2015 e 2016.

Table 3. Effect of leaf removal timing on technological maturity of Sauvignon Blanc (Vitis vinifera L.) in high altitude regions of Santa Catarina State, Brazil. Vintage 2015 and 2016.

\begin{tabular}{ccccccc}
\hline \multirow{2}{*}{ Época de Desfolha } & \multicolumn{2}{c}{$\begin{array}{c}\text { Sólidos Soluvéis } \\
\text { ('Brix) }\end{array}$} & \multicolumn{2}{c}{$\begin{array}{c}\text { Acidez Total } \\
\text { (meq L-1) }\end{array}$} & \multicolumn{2}{c}{$\mathrm{pH}$} \\
\cline { 2 - 7 } & 2015 & 2016 & 2015 & 2016 & 2015 & 2016 \\
\hline Plena Florada & $18,7 \mathrm{a}$ & $18,7 \mathrm{~b}$ & $118,2 \mathrm{a}$ & $137,4 \mathrm{a}$ & $3,08 \mathrm{~ns}$ & $2,89 \mathrm{~ns}$ \\
Grão Chumbinho & $19,1 \mathrm{~b}$ & $18,6 \mathrm{~b}$ & $116,3 \mathrm{a}$ & $130,0 \mathrm{a}$ & 3,11 & 2,87 \\
Grão Ervilha & $19,1 \mathrm{~b}$ & $18,2 \mathrm{~b}$ & $119,1 \mathrm{a}$ & $130,3 \mathrm{a}$ & 3,08 & 2,92 \\
Virada de Cor & $18,2 \mathrm{a}$ & $17,9 \mathrm{a}$ & $127,4 \mathrm{~b}$ & $135,5 \mathrm{a}$ & 3,10 & 2,90 \\
15 dias após Virada de Cor & $18,1 \mathrm{a}$ & $17,9 \mathrm{a}$ & $128,5 \mathrm{~b}$ & $135,3 \mathrm{a}$ & 3,05 & 2,90 \\
Sem Desfolha & $18,6 \mathrm{a}$ & $17,9 \mathrm{a}$ & $137,6 \mathrm{~b}$ & $153,4 \mathrm{~b}$ & 3,07 & 2,91 \\
\hline CV (\%) & 3,3 & 2,0 & 7,0 & 6,8 & 1,2 & 1,3 \\
\hline
\end{tabular}

*Médias seguidas da mesma letra, na coluna, não diferem entre si pelo teste Scott-Knott a 5\% de probabilidade de erro. ns = não significativo.

Alguns trabalhos observaram aumento da concentração de sólidos solúveis (INTRIERI et al. 2008, PONI et al. 2009, GATTI et al. 2012), e isso pode ser explicado pela maior exposição solar ocasionada pela desfolha.

Já para a variável acidez total, verificou-se na safra 2015 menor conteúdo para as plantas submetidas ao manejo da desfolha nos estádios fenológicos plena florada, grão chumbinho e grão ervilha. Já na safra 
2016, verificou-se redução dos valores para todas as épocas de desfolha em relação às plantas não submetidas ao manejo da desfolha. A desfolha precoce, associada a uma alta radiação solar proporciona redução da acidez total titulável, devido à maior degradação do ácido málico (PONI et al. 2008, INTRIGLIOLO et al. 2014, RISCO et al. 2014). Isso ocorre uma vez que altas temperaturas e insolação solar aumentam a temperatura das bagas, que por sua vez aumenta a taxa de respiração, causando a degradação do ácido málico (CONDE et al. 2007).

Para a variável $\mathrm{pH}$ não foram observadas diferenças significativas nas duas safras avaliadas. Outros estudos não observaram efeito da desfolha no pH ou observaram pouco efeito (SCHEINER et al. 2010, MOSSETTI et al. 2016).

Verificou-se, nas duas safras avaliadas, influência das diferentes épocas de desfolha no acúmulo de polifenóis totais (Tabela 4). Na safra 2015, a desfolha realizada no estádio fenológico plena florada resultou em incremento do valor de polifenóis totais extraídos da casca das bagas da videira Sauvignon Blanc. Já as plantas não submetidas ao manejo da desfolha apresentam o menor valor de polifenóis totais. Para a safra 2016, observou-se comportamento distinto da safra 2015, sendo que as desfolhas realizadas nos estádios fenológicos 15 dias após a virada de cor e plantas não submetidas ao manejo da desfolha apresentam os menores valores de polifenóis totais, e o maior valor de polifenóis totais foi observado na desfolha realizada no estádio fenológico grão chumbinho. Contudo, vale ressaltar que nas duas safras avaliadas o manejo da desfolha propiciou aumento no acúmulo de polifenóis totais, exceto o estádio fenológico 15 dias após a virada de cor na safra 2016. Tais resultados estão de acordo com os encontrados por DIAGO et al. (2012), que observou incremento no conteúdo de polifenóis da variedade Tempranillo na Espanha. Além disso, a melhor exposição solar dos cachos da videira e no dossel vegetativo resulta no acúmulo de polifenóis totais, há consenso geral sobre o efeito positivo da radiação solar sobre o acúmulo de polifenóis nas bagas (SPAYD et al. 2002, TARARA et al. 2008, SUN et al. 2012).

Tabela 4. Efeito das épocas de desfolha no conteúdo de polifenóis totais e cor dos cachos da videira Vitis vinifera L. var. Sauvignon Blanc em região de altitude elevada de Santa Catarina. Safra 2015 e 2016.

Table 4. Effect of leaf removal timing on phenolic maturity of Sauvignon Blanc (Vitis vinifera L.) in high altitude regions of Santa Catarina State, Brazil. Vintage 2015 and 2016.

\begin{tabular}{ccccc}
\hline \multirow{2}{*}{ Época de Desfolha } & \multicolumn{2}{c}{$\begin{array}{c}\text { Polifenóis Totais } \\
\text { ( } \mathrm{mg} \mathrm{L}^{-1} \text { ácido gálico) }\end{array}$} & \multicolumn{2}{c}{$\begin{array}{c}\text { Cor } \\
\text { (Abs 420 nm) }\end{array}$} \\
\cline { 2 - 5 } & 2015 & 2016 & 2015 & 2016 \\
\hline Plena Florada & $233,7 \mathrm{c}$ & $248,5 \mathrm{~d}$ & $0,30 \mathrm{~b}$ & $0,28 \mathrm{~b}$ \\
Grão Chumbinho & $192,0 \mathrm{~b}$ & $340,2 \mathrm{f}$ & $0,33 \mathrm{~b}$ & $0,29 \mathrm{~b}$ \\
Grão Ervilha & $203,8 \mathrm{~b}$ & $275,6 \mathrm{e}$ & $0,32 \mathrm{~b}$ & $0,33 \mathrm{~b}$ \\
Virada de Cor & $205,0 \mathrm{~b}$ & $218,4 \mathrm{c}$ & $0,33 \mathrm{~b}$ & $0,28 \mathrm{~b}$ \\
15 dias após Virada de Cor & $165,4 \mathrm{~b}$ & $146,8 \mathrm{a}$ & $0,25 \mathrm{a}$ & $0,19 \mathrm{a}$ \\
Sem Desfolha & $127,2 \mathrm{a}$ & $178,3 \mathrm{~b}$ & $0,21 \mathrm{a}$ & $0,21 \mathrm{a}$ \\
\hline CV (\%) & 7,2 & 4,3 & 8,1 & 7,4
\end{tabular}

*Médias seguidas da mesma letra, na coluna, não diferem entre si pelo teste Scott-Knott a $5 \%$ de probabilidade de erro. ns = não significativo.

Para a variável cor (Abs $420 \mathrm{~nm}$ ) da videira Sauvignon Blanc, verificou-se comportamento similar nas duas safras avaliadas (Tabela 4). As desfolhas realizadas nos estádios fenológicos plena florada, grão chumbinho, grão ervilha e virada de cor resultaram em incremento da coloração das bagas da videira Sauvignon Blanc em 2015 e 2016 em relação à desfolha realizada 15 dias após a virada de cor e as plantas não submetidas ao manejo da desfolha, que apresentam os valores inferiores de cor da extração das cascas. A radiação solar incidente sobre a baga aumenta a sua temperatura e durante o dia pode resultar em $11^{\circ} \mathrm{C}$ maior ou mais comparado com bagas naturalmente sombreadas pelas folhas, de acordo com a hora do dia e as condições climáticas (KLIEWER \& LIDER 1968, REYNOLDS et al. 1986). Tem sido sugerido que a temperatura da casca das bagas tem mais influência no aumento da coloração do que a luz (SPAYD et al. 2002, MORI et al. 2005), com isso, a desfolha propicia aumento da temperatura na casca das bagas de Sauvignon Blanc, promovendo aumento da coloração.

Dessa forma, os resultados observados neste trabalho demonstram que o manejo da desfolha da videira apresentam os benefícios esperados pelo vitivinicultor, tendo em vista o aumento da qualidade final 
da uva para a elaboração de vinhos finos de elevada qualidade. A desfolha da videira deve ser considerada uma prática de manejo indispensável ao vitivinicultor; no entanto, faz-se necessário conhecer as variedades a serem manejadas, as condições climáticas, e a época mais propícia para a realização da desfolha, a fim de obter os benefícios desejados.

\section{CONCLUSÃO}

A produtividade da videira Sauvignon Blanc é superior em plantas desfolhas nos estádios fenológicos grão ervilha e virada de cor. Quando a desfolha é realizada até o estádio fenológico virada de cor, verificase incremento do índice de fertilidade.

Desfolhas precoces, realizadas anteriormente ao estádio fenológico virada de cor, resultaram em incremento no conteúdo de sólidos solúveis, aumento no acúmulo de polifenóis totais e diminuição da acidez total da uva Sauvignon Blanc cultivada em regiões de altitude de Santa Catarina.

\section{AGRADECIMENTOS}

Esta pesquisa foi apoiada financeiramente pela FAPESC (Fundação Estadual de Desenvolvimento Científico e Tecnológico de Santa Catarina), o CNPq e a CAPES (Coordenação de Aperfeiçoamento de Pessoal de Nível Superior ou de Educação).

\section{REFERÊNCIAS}

BAILLOD M \& BAGGIOLINI M. 1993. Les stades repères de la vigne. Revue Suisse de Viticulture Arboriculture Horticulture 25: 7-9.

BLEDSOE AM et al. 1988. Effects of timing and severity of leaf removal on yield and fruit composition of Sauvignon blanc grapevines. American Journal of Enology and Viticulture 39: 49-54.

BORGHEZAN M et al. 2010. Modelos matemáticos para a estimativa da área foliar de variedades de videira à campo (Vitis vinifera L.). Ciência e Técnica Vitivinícola 25: 1-7.

BORGHEZAN M et al. 2014. Phenology and vegetative growth in a new production region of grapevine: case study in São Joaquim, Santa Catarina, Southern Brazil. Open Journal of Ecology 4: 321-335.

BOTELHO RV et al. 2006. Fertilidade de Gemas em Videiras: Fisiologia e fatores envolvidos. Ambiência 2: $129-144$.

BOWEN PA \& KLIEWER WM. 1990. Relationship between the yield and vegetative characteristics of individual shoots of 'Cabernet Sauvignon' grapevines. Journal of the American Society of Horticultural Science 115: 534-539.

BRIGHENTI AF et al. 2013. Caracterização fenológica e exigência térmica de diferentes variedades de uvas viníferas em São Joaquim, Santa Catarina - Brasil. Ciência Rural 43: 1162-1167.

CASPARI HW \& LANG A. 1996. Carbohydrate supply limits fruitset in commercial Sauvignon blanc grapevines. In Proceedings for the Fourth International Symposium on Cool Climate Enology and Viticulture. T. Henick-Kling et al. (eds.), pp. II 9-13. New York State Agriculture Experiment Station, Geneva.

CHORTI E et al. 2010. Effects of different cluster sunlight exposure levels on ripening and anthocyanin accumulation in 'Nebbiolo' grapes. American Journal of Enology and Viticulture 61: 23-30.

CONDE $\mathrm{C}$ et al. 2007. Biochemical changes throughout grape berry development and fruit and wine quality. Food 1: 122.

DIAGO MP et al. 2010. Effects of timing of manual and mechanical early defoliation on the aroma of Vitis vinifera L. Tempranillo wine. American Journal of Enology and Viticulture 61: 382-391.

DIAGO MP et al. 2012. Phenolic composition of Tempranillo wines following early defoliation of the vines. Journal of the Science of Food and Agriculture 92: 925-934.

GATTI M et al. 2012. Effects of cluster thinning and preflowering leaf removal on growth and grape composition in cv. Sangiovese. American Journal of Enology and Viticulture 63: 325-332.

GLORIES Y. 1998. La couleur des vins rouges: les equilibres des anthocyanes et des tanins du Vin. Bordeaux: Actualités. $417 p$.

INTRIERI C et al. 2008. Early defoliation (hand vs mechanical) for improved crop control and grape composition in Sangiovese (Vitis vinifera L.). Australian Journal of Grape and Wine Research 14: 25-32.

INTRIGLIOLO DS et al. 2014. Early defoliation reduces cluster compactness and improves grape composition in Mandó, an autochthonous cultivar of Vitis vinifera from southeastern Spain. Scientia Horticulturae 167: 71-75.

JOGAIAH S et al. 2013. Influence of canopy management practices on fruit composition of wine grape cultivars grown in semi-arid tropical region of India. African Journal of Agricultural Research 8: 3462-3472.

KELLER M \& KOBLET W. 1995. Dry matter and leaf area partitioning, bud fertility and second season growth of Vitis vinifera L.: Responses to nitrogen supply and limiting irradiance. Vitis 34: 77-83.

KLIEWER WM \& LIDER LA. 1968. Influence of cluster exposure to the sun on the composition of 'Thompson Seedless' fruit. American Journal of Enology and Viticulture 19: 175-184.

LEÃO PCS et al. 2016. Canopy management effects on 'Syrah' grapevines under tropical semi-arid conditions. Scientia Agricola 73: 209-216.

LOHITNAVY N et al. 2010. Early leaf removal increases flower abscission in Vitis vinifera Semillon. Vitis 49: 51-53. 
MALINOVSKI LI et al. 2016. Viticultural performance of Italian grapevines in high altitude regions of Santa Catarina State, Brazil. Acta Horticulturae 1115: 203-210.

MARCON FILHO JL et al. 2015. Raleio de cachos sobre o potencial enológico da uva 'Cabernet Franc' em duas safras. Ciência Rural 45: 2150-2156.

MARCON FILHO JL 2016. Sistemas de condução na produção de uvas viníferas e composição química e aromática de vinhos da região de altitude de Santa Catarina. 2016. Tese (Doutorado em Produção Vegetal). Lages: UDESC. 201p.

MORI K et al. 2005. Decreased anthocyanin biosynthesis in grape berries grown under elevated night temperature condition. Scientia Horticulturae 105: 319-330.

MOSSETTI D et al. 2016. Impact of leaf removal after berry set on fruit composition and bunch rot in 'Sauvignon blanc'. Vitis 55: 57-64.

OIV - 2009. Organisation Internationale de la Vigne et du Vin. Recueil des Methodes Internationales d'Analyse des Vins et des Mouts. 424p.

PONI S et al. 2006. Effects of early defoliation on shoot photosynthesis, yield components, and grape quality. American Journal of Enology and Viticulture 57: 397-407.

PONI S et al. 2008. The effect of early leaf removal on whole-canopy gas exchange and vine performance of Vitis vinifera L. 'Sangiovese'. Vitis 47: 1-6.

PONI S et al. 2009. Effects of pre-bloom leaf removal on growth of berry tissues and must composition in two red Vitis vinifera L. cultivars. Australian Journal of Grape and Wine Research 15: 185-193.

REYNOLDS AG et al. 1986. Influence of cluster exposure on fruit composition and wine quality of Seyval blanc grapes. Vitis 25: 85-95.

RIBÉREAU-GAYON P et al. 1998. Traité d'oenologie: microbiologie du vin: vinifications. Paris: Dunod. 185p.

RISCO D et al. 2014. Early defoliation in a temperate warm and semi-arid Tempranillo vineyard: vine performance and grape composition. Australian Journal of Grape and Wine Research 20: 111-122.

RISTIC R et al. 2007. Exclusion of sunlight from Shiraz grapes alters wine colour, tannin and sensory properties. Australian Journal of Grape and Wine Research 13: 3-65.

SPAYD SE et al. 2002. Separation of sunlight and temperature effects on the composition of Vitis vinifera cv. Merlot berries. American Journal of Enology and Viticulture 53: 171-182.

SCHEINER JJ et al. 2010. Impact of severity and timing of basal leaf removal on 3-isobutyl-2-methoxypyrazine concentrations in red winegrapes. American Journal of Enology and Viticulture 61:358-364.

SUN Q et al. 2012. Impact of shoot and cluster thinning on yield, fruit composition, and wine quality of Corot Noir. American Journal of Enology and Viticulture 63: 49-56.

TARARA JM et al. 2008. Berry temperature and solar radiation alter acylation, proportion, and concentration of anthocyanin in Merlot grapes. American Journal of Enology and Viticulture 59: 235-247.

TARDAGUILA $\mathrm{J}$ et al. 2010. Impact of early leaf removal on yield and fruit and wine composition of Vitis vinifera $\mathrm{L}$. Graciano and Carignan. American Journal of Enology and Viticulture 61: 372-381.

TARDAGUILA J et al. 2012. Mechanical yield regulation in winegrapes: comparison of early defoliation and crop thinning. Australian Journal of Grape and Wine Research 18: 344-352.

TONIETTO J \& CARBONNEAU A. 2004. A multicriteria climatic classification system for grape-growing regions worlwide. Agricultural and Forest Meteorology 124: 81-97.

VIANNA LF et al. 2016. Caracterização agronômica e edafoclimáticas dos vinhedos de elevada altitude. Revista de Ciências Agroveterinárias 15: 215-226. 